\title{
Developing a Teacher Cognition on ICT Instrument: A Confirmatory Factor Analysis
}

\author{
Gusti Nur Hafifah $^{1}$, Francisca Maria Ivone ${ }^{2 *}$, and Bambang Yudi Cahyono ${ }^{3}$ \\ ${ }^{1}$ Universitas Muhammadiyah Surabaya; Doctorate Program in Education, Universitas Negeri Malang. \\ ${ }^{2}$ Universitas Negeri Malang \\ ${ }^{3}$ Universitas Negeri Malang \\ *Corresponding author. Email: francisca.maria.fs@um.ac.id
}

\begin{abstract}
Teachers' cognition (knowledge, belief, attitude, and self-efficacy) regarding ICT in ELT needs to be revealed to gain a more comprehensive understanding of their perspective and understanding of incorporating ICT into their everyday instructional activities. This study aims to create Teacher Cognition on ICT (TC-ICT) scales that can be used to assess their cognition level. The paper describes the processes of building the instrument, from domain definition and delimitation to instrument construction. This survey research used an online questionnaire to collect data from 54 respondents and then conducted a confirmatory factor analysis to analyze the results. The validity of the 68 items with a loading factor of more than 6.0 and the AVE score exceeded 5.0 was confirmed by the study. Furthermore, all five factors (knowledge of ICT, belief in ICT, attitude toward ICT, ICT self-efficacy, and ICT perceived use in ELT) had a composite reliability value of better than 0.7 . As a result, all indicators used to measure the variables were found to be reliable. Furthermore, all variables' Cronbach's Alpha values were better than 0.6. Thus, the instrument items were shown to be valid and reliable in assessing the essential variables, and they may be utilized in teacher cognition dimensions and scales studies.
\end{abstract}

Keywords: TC-ICT Instrument, ELT, Confirmatory Factor Analysis

\section{INTRODUCTION}

Researching teacher cognition (TC) is concerned with the unobservable dimension of the teachingteachers mental state of mind that played a role in their instructional choices. It is important to see how the processes of cognition occur entirely in the teachers' minds that might affect their decision and attitude during teaching activities. [1], [2] Borg states that researchers need to study teachers from their psychological processes to recognize the motive behind their teaching work. Thus, it is essential to thoroughly examine what is within the teachers' minds to better understand their teaching behavior in classroom practices.

Cognition is a psychological action or process of acquiring knowledge and understanding through thought, experience, and the senses. It is the thinking process inside the human brain from sensing actions, experiencing events, and gaining information, resulting in ideas or concepts. One's perception and thoughts about one thing are influenced by the information one knows, believes, and feels. Teacher cognition toward teaching is determined by their schooling or educational background, professional coursework, contextual factors, and teaching experiences in classroom practice [3], [4]. Figure 1.1 visualizes Borg's conceptual framework of teacher cognition that includes belief, knowledge, attitudes, assumption, conception, and perception about instructional activities, learning, students, curricula, and materials in teaching.

Studies on teacher cognition in ICT use need to be carried out to understand to what extent teachers use ICT in their English language teaching and how each aspect of cognition significantly contributes to their use of ICT. For example, it is confirmed that knowledge, belief, and attitude are parts of teacher cognition that drive their behavior reflected on their teaching performances [1], [2], [5]-[8]. Similarly, some studies reveal that besides teachers' beliefs and attitudes, their knowledge of technology plays a crucial role in determining their self-efficacy in incorporating technology into teaching [9]-[12]. 


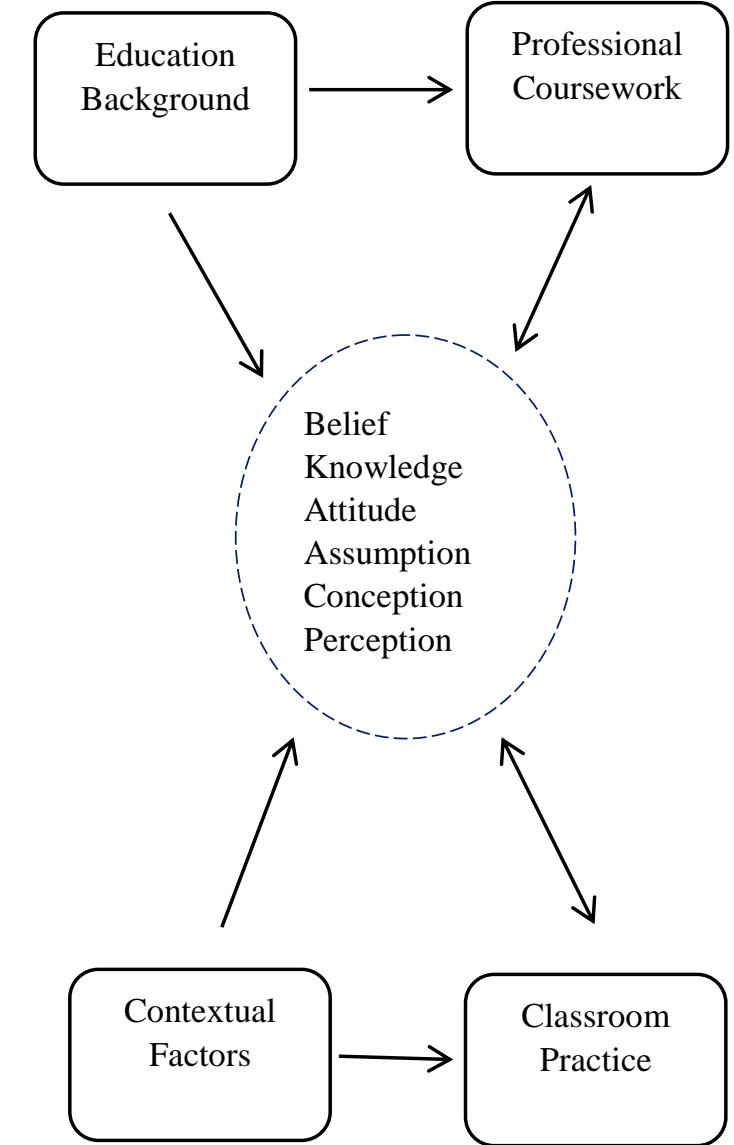

Figure 1. Borg's Conceptual Framework of Teacher Cognition (2003)

Inner connections exist among cognitive factors, according to evaluations of numerous studies on the theoretical framework above. Teachers' understanding of ICT influences their attitude, belief, self-efficacy, and use of ICT. Teachers' ICT self-efficacy adds to their knowledge and experiences with ICT, whereas their belief in ICT contributes to their positive attitude and practices. To summarise, teacher cognition has a major impact on the use of ICT in the classroom.

As only a few instruments have been created to assess teacher cognition and its relationship to ICT in the ELT setting, there are pressing needs to look at the possible factors of teacher cognition that influence teacher use of ICT in ELT. The goal of this research is to develop Teacher Cognition on ICT (TC-ICT) measures that can be used to assess teachers' cognition. It specifically looks at four aspects of teacher cognition: knowledge, belief, attitude, and self-efficacy. Each variable is measured through a questionnaire with different scales of measurements.

Some previous studies and theories were reviewed and analyzed as the basis of this research instrument construction. Four variables of teacher cognition, i.e., knowledge, belief, attitude, and self-efficacy, were identified as the potential aspects that formed teacher cognition. The following research questions are proposed in order to build a valid and reliable instrument that can be used to measure teacher cognition about ICT in an ELT context.

(1) What are the steps of constructing valid and reliable instruments?

(2) Are the questionnaire items constructed valid and reliable to measure the variables of Teacher Cognition on ICT (TC-ICT)?

\section{METHOD}

The instrument was constructed by analyzing prior teacher cognition studies and theories and constructing a blueprint of study factors, dimensions, and indicators. Following that, the blueprint was used to create questionnaire items and scales, which were then validated and revised by experts. The questionnaire was disseminated using Google Form, and the results were statistically analyzed using confirmatory factor analysis. The study's participants were 54 English lecturers with a master's degree who taught at the university level.

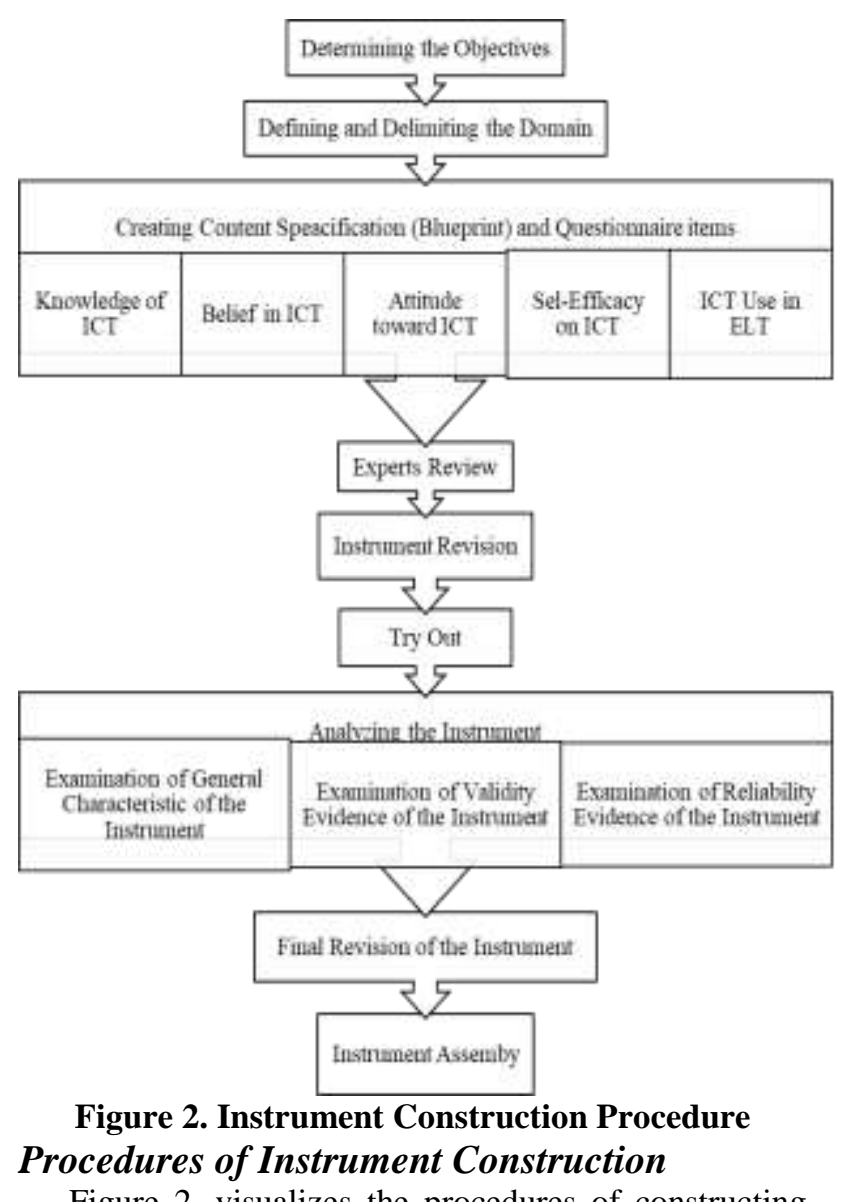

Figure 2. visualizes the procedures of constructing the questionnaire to create a valid and reliable instrument for data collection [13]. Nine steps were completed till the instrument is ready to use. The first step is Determining the Objective. This step is critical since the instrument developed for this study was created to meet the research goal of examining elements of teacher cognition and their links to ICT use. The second step is Defining and Delimiting the Domain. At this stage, the theoretical framework was developed to include the idea of teacher cognition and its relation to 
teachers' ICT practices in ELT, resulting in a hypothesis model of relationship. The dimensions of each study variable were then established and delimited in a methodical manner. In this research, the study of teacher cognition was focused on the following cognition variables: knowledge, belief, attitude, self-efficacy, and the usage of ICT in the ELT setting. Meanwhile, some aspects of teacher cognition, such as assumption, conception, and perception, were not studied.

The third step is Content Specification (Blueprint). As a preliminary analysis, the content specification of each variable was developed to build the questionnaire items. Variables, dimensions, indicators, item numbers, the total number of items for each variable, and the item percentage were all included in the blueprint table. Knowledge, belief, attitude, self-efficacy, and ICT use were the five variables studied. Each variable was divided into many dimensions, each of which included several indicators. Finally, item statements were generated based on the indicators, which were classified into some reflecting indicators that represent the latent variables' real state.

The fourth step, Experts Review, and Validation was used to check the instrument's content and construct validity before using it on a few samples. The instrument and design were evaluated and verified by three experts with various areas of competence (ICT in ELT, assessment, and educational psychology) and at least doctoral credentials. The validation instruments were supplied to all three experts in the form of three documents, i.e., questionnaire blueprint, questionnaire, and expert validation sheet.

Based on the assessment sheet supplied individually and independently from other experts, each expert reviewed and verified the questionnaire. The expert validation rubric was used to assess the questionnaire's content, format, language, and timeliness, using four scales of measurement (suitable, pretty appropriate, somewhat appropriate, and inappropriate). The extent to which the questionnaire adequately and thoroughly reflected the substance of the variables necessary to assess, relevant to the survey goals, was tested for content validity.

References and a summary of the theoretical framework were supplied to the experts for them to assess the content appropriateness of the construct definition from the conceptual background. To generate more qualifying items, they assessed the questionnaire using the teacher cognition design and conceptual framework and linked them to the instrument's variables, dimensions, and indicators. They also checked to see if the instrument could assess particular qualities related to teacher cognition and referred to the theory that underpins this research. The instrument was revised several times until it fulfilled the proper scale of assessment requirements. The review and validation procedures were completed in one month.

Instrument Revision is the fifth phase in the instrument construction procedure. At this stage, the instrument was revised in response to the experts' comments that highlighted the need for minor changes to its content and format. Because they were excessively lengthy or confusing, some questionnaire item statements were modified and shortened. From the original 87 items, only 83 remained after the revision. The revised instrument was discussed with experts many times until no more changes were needed and the instrument met the standards of the evaluation sheet; it was then suitable to use to gather data.

Trying Out the Instrument is the sixth stage. The tryout was carried out to determine the empirical validity and reliability of the research instrument (questionnaire) for it to accurately gather data for teacher cognition study. The redesigned instrument was tested on several samples of English teachers at the university level. The tryout participants received the questionnaire via email. The tryout was held to discover issues with technical aspects such as the clarity of each item being tested, the clarity of the instruction, and the allocation of time.

Analyzing the Instrument is the eighth stage. It was designed to test the instrument's empirical validity and reliability in three phases: An assessment of the instrument's general features, an evaluation of the instrument's validity evidence, and an analysis of the instrument's reliability measurement. Confirmatory factor analysis was utilized in the validity and reliability analysis. Meanwhile, respondents were requested to provide feedback on the questionnaire by filling out a respondent evaluation form, which was used to examine the instrument's overall features. To determine if the respondents experienced difficulties or found the survey inconvenient, the Lawshe scale was used, which ranged from agreeing, slightly agreeing, not sure, somewhat disagreeing, and disagreeing. The overall evaluation and feedback from the respondents provided useful input for the questionnaire's general characteristics. It may also be classified as part of the 'face validity' stage, which is concerned with the entire look of the questionnaire as judged by the respondents as viewers. Their suggestions were used as a reference for revising the instrument.

The eighth step is Final Revision. In this stage, the instrument was revised based on the validity and reliability test result. Some items that are neither valid nor reliable were removed. The final step is Instrument Assembly. It involves creating and structuring the valid and reliable questionnaire items into a fixed instrument in a word document and then converting them to an online questionnaire format (Google Form).

\section{RESULTS AND DISCUSSION Confirmatory Factor Analysis: Validity and Reliability Measurement.}

Confirmatory Factor Analysis (CFA) was employed to measure the construct validity of the instrument. CFA enabled the researchers to determine whether the instrument was a valid measurement model or not. This analysis was also able to confirm which indicators were 
valid and properly constructed based on the theoretical concepts. Furthermore, CFA evaluated whether the indicators of the questionnaires were able to represent the dimensions and measure the latent variables. The analysis was to assure that each variable was tested and appropriately suitable with the blueprint.

Table 1. The Criteria of Validity Measurement of the Instrument [14]

\begin{tabular}{|c|c|}
\hline Measures & Criteria \\
\hline $\begin{array}{l}\text { Convergent } \\
\text { Validity }\end{array}$ & $\begin{array}{l}\text { The convergent validity for the } \\
\text { instrument is achieved if the loading } \\
\text { factor score of each item is positive } \\
\text { and greater than } 0.6 \text { or when all values } \\
\text { of AVE exceed } 0.50 \text {. }\end{array}$ \\
\hline $\begin{array}{l}\text { Discriminant } \\
\text { Validity }\end{array}$ & $\begin{array}{l}\text { The Discriminant Validity is achieved } \\
\text { when each item has a loading factor } \\
\text { score greater than the correlation score } \\
\text { between the indicators and other } \\
\text { variables, then the item is valid in } \\
\text { measuring the corresponding variable. }\end{array}$ \\
\hline
\end{tabular}

The convergent and discriminant validity testing was conducted to examine whether each item was valid in measuring the variables. Eighty-three items were measuring four variables. There were 15 items with a loading factor score that was not greater than 0.6. The score means that the fifteen items were not valid in measuring the variables. Those invalid items were four items measuring knowledge of ICT variable (X.1.1.3, X.1.2.3, X.3.2.1, X. 3. 2.2), three items measuring belief in ICT variable (Z1.1.4, Z1.2.1.5, Z1.2.2.5), four items measuring self-efficacy variable (Z3.2.2, Z3.3.2, Z3.2.1, Z3.3.1) and four items measuring the perceived use of ICT variable (Y1.1, Y1.4, Y2.1, Y2.2). Finally, 68 items were considered valid in measuring the corresponding variables, as the loading factor was greater than 6.0 and the AVE score exceeded 5.0. These 68 items also fulfilled the discriminant validity criteria because the loading factor scores were greater than the correlation scores between the indicators and other variables.

The consistency of the answers collected from the questionnaire is referred to as reliability. The criteria listed in Table 2 were used to complete the CFA reliability procedures. Based on the reliability measurement in confirmatory factor analysis, the composite reliability score of all five variables (knowledge of ICT, belief in ICT, attitude toward ICT, ICT self-efficacy, and ICT perceived use in ELT) was more than 0.7. As a result, all of the indicators used to measure the variables were accurate. Furthermore, all variables' Cronbach's Alpha values were greater than 0.6. As a result, all indicators were accurate in measuring the factors that were present.
Table 2. The Criteria of Reliability Measurement of the Instrument [14]

\section{Measures Criteria}

Cronbach's Internal Reliability indicates how

Alpha strong the measuring items are holding together in measuring the respective construct. This reliability is achieved when the value of Cronbach's Alpha exceeds 0.6.

Composite The Composite Reliability indicates Reliability the reliability and internal consistency of a latent construct. A value of $\mathrm{CR}>$ 0.7 is required to achieve composite reliability for a construct.

\section{The Items Scale}

Six sections in the developed questionnaire measure four independent factors of teacher cognition and one dependent variable of ICT use in ELT. The first section of the questionnaire contains 22 items that reveal the research's independent variable, i.e., teachers' ICT knowledge. The second section has 14 questions that reveal the intervening variable, i.e., teachers' ICT belief. The third section consists of 15 questions that aim at determining teachers' attitudes toward ICT. The fourth section consists of nine questions designed to assess teachers' ICT self-efficacy. The dependent variable, teachers' perceived use of ICT in ELT, is established in the fifth section, which comprises eight items. For those five variables, all of the questionnaire items are in multiple-choice format. Respondents can only choose one of four possible answers, and each variable has a separate measurement scale. Finally, the demographic questions are addressed in the sixth part. Respondents are asked 10 demographic questions regarding their email addresses, city of residence, gender, age, teaching institution, teaching department, duration of teaching experience, educational background, last degree completed, and teachers' ICT implementation issues.

To round out the instrument, a few items regarding respondents' demographic data are included in the concluding section of the questionnaire. Categorical information about teachers' educational backgrounds, length of teaching experience, ICT or other technology application training experiences, institutions, geographical region, gender, and age is also included. The difficulties that teachers face while using ICT in ELT are also enquired. Technological issues, institutional support, timing, and facility are also included as indicators for implementation problems.

\section{Knowledge of ICT Scale}

Knowledge of ICT is defined as teachers' perceived knowledge and understanding of ICT integration in language teaching. The knowledge investigated in this study is not concerned with teachers' actual knowledge or competence of using ICT in language teaching, but on their perceived knowledge, namely the kinds of ICT applications they know, and how far they think they know and are capable of integrating them in their daily 
teaching practice. The questionnaire uses the scale of measurement level starting from excellent, good, fair, and no idea to measure teachers' level of understanding or knowledge about ICT.

This first section covers questions that reveal teachers' perceived knowledge and understanding of ICT for language teaching. Upon reviewing previous studies' results in the theoretical framework, the questionnaire items in this section were constructed by adapting previous instruments exploring teachers' Knowledge of ICT [15]-[20]. Teachers' knowledge of ICT is measured using four scale options: excellent, good, fair, and no idea, to identify the teachers' level of understanding about ICT. In addition, the knowledge variable is measured based on four dimensions of knowledge, i.e., factual, conceptual, procedural, and metacognitive. This variable is to reveal teachers' level of understanding about ICT; teachers' familiarity toward ICT; types of ICT tools and applications (hardware, software, internet, audio-visual material, technological tasks); a variety of social software applications (e.g., blogs, Facebook, YouTube, Google tools, Messenger, Skype, E-learning materials, and others search engines), and kinds of ICT activities.

In contrast to the previous theory of knowledge of ICT, which is mainly based on the TPACK framework [21], [22], this study proposes new construct items to reveal teachers' technological knowledge of ICT based on the knowledge taxonomy [15]. As a result, the four aspects of ICT knowledge give a clearer picture of teachers' factual, conceptual, procedural, and metacognitive knowledge of ICT tools and applications used in ELT. However, there are no construct items that can measure teachers' ICT literacy's actual knowledge or capacity since the constructs used in the developed questionnaire measure teachers' perceived knowledge based on their perception.

\section{Belief in ICT Scale}

Belief in ICT is defined as teachers' belief and acceptance of the importance of ICT and the motives of integrating ICT in their teaching. The questionnaire items of teachers' beliefs are developed based on three dimensions: existential, evaluative, and prescriptive belief. This second section of the questionnaire is an adaptation of two previous studies [23], [24] exploring teachers' belief in ICT. The measurement scale employs a Likert scale which options ranging from strongly agree, agree, disagree, to strongly disagree. More specifically, the dimension of belief in ICT covers existential belief, evaluative belief, and prescriptive belief about ICT implementation for English language teaching at the higher education level.

\section{Attitude toward ICT Scale}

Attitude toward ICT is teachers' settled way of thinking or feeling about ICT implementation in ELT. Teachers' preferences, interest, and like/dislike about ICT are included in the questionnaire to determine whether teachers have a positive or negative attitude toward ICT integration. The variable of attitude investigated in the third section of the questionnaire is adapted from several relevant studies [16], [18], [20], [25]-[27]. The measurement scale employed a Likert scale with the options ranging from strongly agree, agree, disagree, to strongly disagree. It uses the same scales as those in the belief in ICT section since it has similar characteristics with the Belief in ICT variables. The main difference is that the items in this section assess different dimensions of attitude that reveal teachers feeling about ICT for language teaching, such as their likes and dislikes about ICT or teachers' preferences and aversion to ICT and their feeling of necessity and willingness in applying ICT in their language teaching.

\section{ICT Self-Efficacy Scale}

ICT Self-Efficacy is the teachers' perception of their ability to integrate ICT into the English teachinglearning process. The questionnaire measures how well teachers are capable and confident in knowing, integrating, and solving the problem related to ICT use in their teaching. The fourth section of the questionnaire covers questions about teachers' self-efficacy on ICT which are adapted from several previous studies [10], [11], [28]-[31]. The self-efficacy variable is also measured by the same scale of strongly agree, agree, disagree, and strongly disagree to ease the respondents in answering the questionnaire items. However, the statement items in this section are designed to reveal teachers' confidence and perception of their ability in implementing ICT in their daily teaching based on three dimensions: the confidence in knowing self-ability, the confidence in doing or implementing ICT in language teaching, and the confidence in solving problems with or related to ICT use.

Furthermore, this study also contributes to a new valid and reliable construct to measure ICT selfefficacy. Many previous studies referred to Bandura's theory of self-efficacy, exploring four dimensions: successful performance attainment, vicarious experience, social influences and persuasions, and physiological or affective states [9], [31], [32]. Other studies focused on the three dimensions of self-efficacy related to the use of computer and smartphone acceptance: magnitude, strength, and generalisability in completing ICT tasks [33]-[35]. Based on the results of the present study, a new valid and reliable construct of ICT self-efficacy, which is developed based on the three new dimensions of self-efficacy: the confidence in knowing, doing, and solving problems related to the use of ICT in ELT, can be added to the results of previous studies.

\section{ICT Use in ELT}

ICT Perceived Use in ELT refers to claims made on all kinds of ICT activities, tools, and applications implemented in ELT in the higher education contexts. ELT in this study is not limited to the teaching of English as language skills and components but also to 
the teaching of other subjects in the curriculum of the English department undergraduate programs. Kinds of ICT tools and applications in the instrument refer to ICT tools (e.g., computer, laptop, smartphones, LCD projectors, interactive whiteboard, flash-disks, scanner, printer, digital camera, loudspeaker, virtual reality glasses, to name a few) used in ELT. Meanwhile, kinds of ICT software and applications include the internet, websites, electronic resources, multimedia, online platform, learning management systems (LMS), educational games, social media, teleconferencing, net meeting, and other computer applications programs. ICT-supported activities for language teaching, such as finding teaching resources and materials, explaining lessons, giving an assignment, and monitoring students' progress and assessment, are also asked in the questionnaire items. The ICT use is measured based on the frequency of use in teaching activities. Thus, the questionnaire measures how often teachers apply ICT in ELT based on occurrences, i.e., a few times a week, few times a month, few times a semester, and never.

The items in the fifth section of the developed questionnaire are adapted from several relevant studies [28], [36], [37]. This section reveals information about teachers' ICT implementation in their teaching activities, based on two dimensions: types of ICT tools and applications and kinds of ICT activities in ELT. The four scales used in the options specifically measure the frequency of ICT use, i.e., a few times a week, few times a month, few times a semester, and never. The scales of measurement are constructed based on the duration of teaching activities in a higher education setting, in which lecturers teach specific courses weekly and end up in a semester.

\section{CONCLUSIONS AND LIMITATIONS}

The instrument developed in this study is shown to be valid and reliable for measuring teacher cognitive dimensions and scales. It measures four variables of teacher cognition and one variable of ICT use in ELT. The first variable is knowledge of ICT that consists of four dimensions and 22 items. The second variable is Belief in ICT that covers three dimensions and 14 items. The third variable is the attitude toward ICT that consists of three dimensions and 15 items. The fourth variable is ICT self-efficacy that covers three dimensions and nine items. The last variable is ICT use in ELT that covers two dimensions and eight items. The result indicates that all 68 items were valid and reliable in measuring the existing variables, and the instrument was appropriate to use to collect data for the research.

This study focuses on the four variables of teacher cognition: knowledge, belief, attitude, and self-efficacy. Some of the aspects of teacher cognition such as assumption, conception, and perception are not studied since there are limited previous studies that explored teachers' conception and assumption about ICT in ELT compared to the other cognition variables such as perception, knowledge, belief, attitude, and selfefficacy that are used as a theoretical basis for the present study. Moreover, there are also limited instruments that empirically measure teachers' assumptions, conceptions, and perceptions about ICT in ELT [36], [39]-[44].

Belief and attitude are primarily associated with assumption and perception, and conception is often equated with knowledge [45]-[48]. Furthermore, the difference between cognition and perception is also a point of contention. Perception is said to deal with the sensory process, whereas cognition is seen to deal with the human brain's thinking process, although numerous studies have called into question the distinctions between the two because they are so closely connected [49]-[52]. As a result, the examined variable excludes assumptions, conceptions, and perceptions. Because the focus of the tryout in this study is on university-level English teachers, future research needs to apply the instrument to a larger sample size to obtain a more valid and reliable conclusion.

\section{AUTHORS' CONTRIBUTIONS}

This publication is the outcome of a dissertation project in which the first author $(\mathrm{GH})$ was the primary contributor in writing the text and gathering research data, while the co-authors (BYC) and (FMI) served as supervisors and contributed to the data analysis and review mechanisms. The final manuscript was reviewed and approved by all writers.

\section{ACKNOWLEDGMENTS}

This publication is supported by PNBP Universitas Negeri Malang 2021 grant scheme. Highest appreciation to all English teachers in higher education institutions who voluntarily participated in the tryout.

\section{REFERENCES}

[1] S. Borg, "Introducing Language Teacher Cognition," Cambridge Guide. to Second Lang. Teach. Educ., pp. 163-170, 2009, doi: 10.1097/00000433-198206000-00020.

[2] S. Borg, Teacher Cognition and Language Education: Research and Practice. New York, USA: Bloomsbury Academic, 2015.

[3] S. Borg, "Teacher Cognition in Language Teaching: A Review of Research on What Language Teachers Think, Know, Believe, and Do," Lang. Teach., vol. 36, no. 2, pp. 81-109, 2003, doi: 10.1017/S0261444803001903.

[4] D. Woods, "Review of Teacher Cognition and Language Education: Research and Practice," Can. Mod. Lang. Rev., vol. 65, pp. 511-513, 2009.

[5] R. Barnard and A. Burns, Eds., Researching Language Teacher Cognition and Practice: International Case Studies. Multilingual Matters, 2012.

[6] S. Borg, "Current Approaches to Language Teacher Cognition Research: A Methodological Analysis.," in Researching Language Teacher Cognition and Practice, R. Barnard and A. Burns, Eds. Multilingual Matters, 2012, pp. 11-29. 
[7] S. Borg, "Teacher Cognition in Grammar Teaching: A Literature Review," Lang. Aware., vol. 12, no. 2, pp. 96-108, 2003, doi: 10.1080/09658410308667069.

[8] S. Borg, I. Clifford, and K. P. Htut, "Having an EfECT: Professional Development for Teacher Educators in Myanmar," Teach. Teach. Educ., vol. 72, pp. 75-86, May 2018, doi: 10.1016/j.tate.2018.02.010.

[9] J. T. Abbitt, "An Investigation of the Relationship between Self-Efficacy Beliefs about Technology Integration and Technological Pedagogical Content Knowledge (TPACK) among Preservice Teachers," J. Digit. Learn. Teach. Educ., vol. 27, no. 4, pp. 134-143, 2011, doi: 10.1080/21532974.2011.10784670.

[10] I. Y. Kazu and P. Erten, "Teachers' Technological Pedagogical Content Knowledge Self-Efficacies," J. Educ. Train. Stud., vol. 2, no. 2, pp. 126-144, 2014, doi: 10.11114/jets.v2i2.261.

[11] H. Keser, F. Gizem, K. Y1lmaz, and R. Y1lmaz, "TPACK Competencies and Technology Integration Self-Efficacy," Elem. Educ. Online, vol. 14, no. 4, pp. 1193-1207, 2015, doi: 10.17051/io.2015.65067.

[12] H.-W. Liu, J.-C. J. Jeong, C. Chun-Hsi, and M. Fang, "What Factors Affect Teachers in Taiwan in Becoming More Involved in Professional Development? A Hierarchical Linear Analysis," Hum. Resour. Dev. Q., vol. 25, no. 3, pp. 381-400, 2014, doi: 10.1002/hrdq.

[13] G. H. Sulistyo, EFL Learning Assessment at Schools. An Introduction to its Basic Concepts and Principles. Malang: CV. Bintang Sejahtera, 2015.

[14] J. F. Hair, G. T. M. Hult, C. Ringle, and M. Sarstedt, A Primer on Partial Least Squares Structural Equation Modelling, Second ed. Thousand Oaks: Sage, 2017.

[15] L. W. Anderson and D. R. Krathwohl, A Taxonomy for Learning, Teaching, and Assessing: A Revision of Bloom's Taxonomy of Educational Objectives. Boston, MA.: Allyn \& Bacon. Pearson Education Group, 2001.

[16] M. Kandasamy, P. Bt, and H. M. Shah, "Knowledge, Attitude and Use of ICT Among ESL Teachers," Gse J. Educ., pp. 185-199, 2013.

[17] S. Kontkanen, P. Dillon, T. Valtonen, S. Renkola, M. Vesisenaho, and P. Väisänen, "Pre-Service Teachers' Experiences of ICT in Daily Life and Educational Contexts and their ProtoTechnological Pedagogical Knowledge," Educ. Inf. Technol., vol. 21, no. 4, pp. 919-943, 2014, doi: 10.1007/s10639-014-9361-5.

[18] T. K. R. Singh and S. Chan, "Teacher Readiness On ICT Integration In Teaching-Learning: A Malaysian Case Study,” Int. J. Asian Soc. Sci., vol. 4, no. 7, pp. 874-885, 2014.

[19] J. Son, T. Robb, and I. Charismiadji, "Computer Literacy and Competency: A Survey of Indonesian Teachers of English as a Foreign Language," Call-
Ej, vol. 12, no. 1, pp. 26-42, 2011, [Online]. Available:

http://eprints.usq.edu.au/18371/3/Son_Robb_Chari smiadji_Doc_18371.pdf.

[20] E. Tezci, "Attitudes and Knowledge Level of Teachers in ICT use: The Case of Turkish Teachers," J. Hum. Sci., vol. 7, no. 2, pp. 19-44, 2010, [Online]. Available: http://search.ebscohost.com/login.aspx?direct=true $\& \mathrm{db}=\mathrm{a} 9 \mathrm{~h} \& \mathrm{AN}=52490103 \&$ site $=$ ehost-live .

[21] Chai, C. S, J. H. L. Koh, and C.-C. Tsai, "A Review of Technological Pedagogical Content Knowledge," Educ. Technol. Soc., vol. 16, no. 2, pp. 31-51, 2013, doi: 10.1111/j.13652729.2010.00372x.

[22] P. Mishra and M. J. Koehler, "Technological Pedagogical Content Knowledge: A Framework for Teacher Knowledge," Teachers College Record, vol. 108, no. 6. pp. 1017-1054, 2006, DOI: 10.1111/j.1467-9620.2006.00684.x.

[23] D. D. Holland and R. T. Piper, "A technology integration education (TIE) model: Millennial preservice teachers' motivations about technological, pedagogical, and content knowledge (TPACK) competencies," J. Educ. Comput. Res., vol. 51, no. 3, pp. 257-294, 2014, doi: 10.2190/EC.51.3.a.

[24] A. Sadaf and B. L. Johnson, “Teachers' Beliefs About Integrating Digital Literacy Into Classroom Practice: An Investigation Based on the Theory of Planned Behavior,' J. Digit. Learn. Teach. Educ., vol. 33, no. 4, pp. 129-137, 2017, doi: 10.1080/21532974.2017.1347534.

[25] S. A. Gyamfi, "Pre-Service Teachers ' Attitude towards Information and Communication Technology Usage: A Ghanaian survey," Int. J. Educ. Dev. using Inf. Commun. Technol., vol. 13, no. 1, pp. 52-69, 2017.

[26] M. Hismanoglu, “The Impact of a Curricular Innovation on Prospective EFL Teachers' Attitudes towards ICT Integration into Language Instruction," Int. J. Instr., vol. 5, no. 1, pp. 183 202, 2012, [Online]. Available: http://www.eric.ed.gov/ERICWebPortal/detail?acc no=ED529107.

[27] H. Liu, C.-H. Lin, and D. Zhang, "Pedagogical Beliefs and Attitudes toward Information and Communication Technology: A Survey of Teachers of English as a Foreign Language in China," Comput. Assist. Lang. Learn., vol. 8221, no. July, pp. 1-21, 2017, doi: 10.1080/09588221.2017.1347572.

[28] D. Bozdoğan and R. Özen, "Use of ICT Technologies and Factors Affecting Pre-Service ELT Teachers' Perceived ICT Self-Efficacy," Turkish Online J. Educ. Technol., vol. 13, no. 2, pp. 186-196, 2014.

[29] E. Choi and J. Lee, "EFL teachers' self-efficacy and teaching practices," ELT J., vol. 72, no. 2, pp. 175-186, 2018, doi: 10.1093/elt/ccx046. 
[30] Y. Lee and J. Lee, "Enhancing Pre-Service Teachers' Self-Efficacy Beliefs for Technology Integration Through Lesson Planning Practice," Comput. Educ., vol. 73, pp. 121-128, 2014, doi: 10.1016/j.compedu.2014.01.001.

[31] L. Wang, P. A. Ertmer, and T. J. Newby, "Increasing Pre-Service Teachers' Self-Efficacy Beliefs for Technology Integration," J. Res. Technol. Educ., vol. 36, no. 3, pp. 231-250, 2004, doi: 10.1080/15391523.2004.10782414.

[32] A. Bandura, "Guide for Constructing Self-Efficacy Scales," in Self-Efficacy Beliefs of Adolescents, 2006, pp. 307-337.

[33] K. Chen, J. V. Chen, and D. C. Yen, "Dimensions of self-efficacy in the study of smartphone acceptance," Comput. Stand. Interfaces, vol. 33, no. 4, pp. 422-431, 2011, doi: 10.1016/j.csi.2011.01.003.

[34] D. R. Compeau and C. A. Higgins, "Computer Self-Efficacy: Development of a Measure and Initial Test,” MIS Q., vol. 19, no. 2, p. 189, 1995, doi: $10.2307 / 249688$.

[35] J. B. Thatcher, J. C. Zimmer, M. J. Gundlach, and D. H. McKnight, "Internal and External dimensions of Computer Self-Efficacy: An Empirical Examination," IEEE Trans. Eng. Manag., vol. 55, no. 4, pp. 628-644, 2008, doi: 10.1109/TEM.2008.927825.

[36] G. Li and X. Ni, "Primary EFL teachers' technology use in China: Patterns and perceptions," RELC J., vol. 42, no. 1, pp. 69-85, 2011, doi: 10.1177/0033688210390783.

[37] A. Muslem, Y. Q. Yusuf, and R. Juliana, "Perceptions and Barriers to ICT Use Among English Teachers in Indonesia," Teach. English with Technol., vol. 18, no. 1, pp. 3-23, 2018, [Online]. Available: http://www.tewtjournal.org.

[38] Partnership for 21st Century Learning, "Framework for 21st Century Learning," 2015. doi:

http://www.21stcenturyskills.org/documents/frame work_flyer_updated_jan_09_final-1.pdf.

[39] B. Akkonyunlu and M. Y. Soylu, "A Study of Student's Perception in a Blended Learning Environment Based on Different Learning Styles," Educ. Technol. Soc., vol. 11, no. 1, pp. 183-193, 2008, doi: 10.1007/s00217-010-1351-2.

[40] J. Barnes and S. Kennewell, "Investigating Teacher Perceptions of Teaching ICT in Wales," Educ. Inf. Technol., vol. 22, no. 5, pp. 2485-2497, 2017, doi: 10.1007/s10639-016-9549-y.

[41] J. Borup, C. Chambers, and R. Srimson, "Online teacher and on-site facilitator perceptions of parental engagement at a supplemental virtual high school," Int. Rev. Res. Open Distance Learn., vol. 20, no. 2, pp. 79-95, 2019, doi: 10.19173/irrodl.v20i2.4237.

[42] P. Luik, M. Taimalu, and R. Suviste, "Perceptions of Technological, Pedagogical and Content Knowledge (TPACK) among Pre-Service Teachers in Estonia,” Educ. Inf. Technol., vol. 23, no. 2, pp. 741-755, 2018, doi: 10.1007/s10639-017-9633-y.

[43] A. Mwalongo, “Teachers' perceptions about ICTs for teaching, professional development, administration, and personal use," Int. J. Educ. Dev. using ICT, vol. 7, no. 3, pp. 36-49, 2012.

[44] A. D. Olofsson and J. O. Lindberg, "Assumptions about participating in teacher education through the use of ICT," Campus-Wide Inf. Syst., vol. 22, no. 3, pp. 154-161, 2005, doi: $10.1108 / 10650740510606153$.

[45] D. Alt, "Science teachers' conceptions of teaching and learning, ICT efficacy, ICT professional development and ICT practices enacted in their classrooms," Teach. Teach. Educ., vol. 73, pp. 141-150, 2018, doi: 10.1016/j.tate.2018.03.020.

[46] E. Griva and D. Chostelidou, "English Language Teachers' Conceptions and Attitudes to Multilingual Development in Education," Procedia - Soc. Behav. Sci., vol. 15, pp. 1780-1785, 2011, doi: 10.1016/j.sbspro.2011.04.002.

[47] S. Huimin and L. Yi, "Conception of Teachers' Beliefs about Teaching with ICT and the Status in Nanjing," Proc. - 2015 Int. Conf. Educ. Innov. Through Technol. EITT 2015, pp. 204-209, 2016, doi: 10.1109/EITT.2015.50.

[48] A. D. Olofsson and J. O. Lindberg, "Assumptions about Participating in Teacher Education through the Use of ICT," Campus-Wide Inf. Syst., vol. 22, no. 3, pp. 154-161, 2005, doi: 10.1108/10650740510606153.

[49] A. Michel, "Cognition and Perception: Is There Really a Distinction?," 2019, [Online]. Available: https://www.psychologicalscience.org/observer/co gnition-and-perception-is-there-really-a-distinction.

[50] C. Montemayor and H. H. Haladjian, "Perception and Cognition are Largely Independent, but Still Affect Each Other in Systematic Ways: Arguments from Evolution and the Consciousness-Attention Dissociation," Front. Psychol., vol. 8, no. JAN, pp. 1-15, 2017, doi: 10.3389/fpsyg.2017.00040.

[51] A. Raftopoulos, Cognition and Perception: How Do Psychology and Neural Science Inform Philosophy, 1 edition. A Bardford Book, 2009.

[52] M. C. Tacca, "Commonalities between Perception and Cognition," Front. Psychol., vol. 2, no. NOV, pp. 1-10, 2011, doi: 10.3389/fpsyg.2011.00358. 